\title{
Controlled Ascent from the Surface of an Asteroid
}

\author{
Haijun Shen, Carlos M. Roithmayr, and David M. Cornelius ${ }^{\ddagger}$
}

\begin{abstract}
The National Aeronautics and Space Administration (NASA) is currently investigating a conceptual robotic mission to collect a small boulder up to $4 \mathrm{~m}$ in diameter resting on the surface of a large Near Earth Asteroid (NEA). Because most NEAs are not well characterized, a great range of uncertainties in boulder mass properties and NEA surface characteristics must be considered in the design of this mission. These uncertainties are especially significant when the spacecraft ascends with the boulder in tow. The most important requirement during ascent is to keep the spacecraft in an upright posture to maintain healthy ground clearances for the two large solar arrays. This paper focuses on the initial stage (the first $50 \mathrm{~m}$ ) of ascent from the surface. Specifically, it presents a sensitivity study of the solar array ground clearance, control authority, and accelerations at the array tips in the presence of a variety of uncertainties including various boulder sizes, densities, shapes and orientations, locations of the true center of mass, and push-off force distributions. Results are presented, and appropriate operations are recommended in the event some of the off-nominal cases occur.
\end{abstract}

\section{Introduction}

In recent years the National Aeronautics and Space Administration (NASA) has been considering a conceptual robotic mission to collect a small Near-Earth Asteroid (NEA) or a small boulder resting on the surface of a large NEA, and transport it to an orbit in the Earth-Moon system. The latter option is referred to as the Asteroid Robotic Redirect Mission (ARRM) Alternate Concept [1]. Such a mission would lead to greater scientific understanding of NEAs and could demonstrate concepts for planetary defense. Dynamics and control during various phases of the mission when the spacecraft is in the vicinity of the asteroid are discussed in Refs. [2] and [3]. Specifically, initial approach, hover, spacecraft spin-up, descent, ascent (in the case of boulder retrieval), and de-spin are examined in order to determine the velocity increments and control force and torque that must be provided by a Reaction Control System (RCS), and the mass of the propellant that will be consumed. The present paper is concerned with retrieving a boulder from the surface of a large NEA; in particular, the focus is on ascent from the NEA and the dynamics and control of

*Analytical Mechanics Associates, Inc., 21 Enterprise Parkway, Suite 300, Hampton, VA 23666, USA, Tel: +1 757 865 0000, email: shen@ama-inc.com

${ }^{\dagger}$ NASA Langley Research Center, Vehicle Analysis Branch, MS 451, 1 North Dryden Street, Hampton, VA, 23681, USA, Tel: +1 757864 6778, email: carlos.m.roithmayr@nasa.gov

$\ddagger$ Analytical Mechanics Associates, Inc., 21 Enterprise Parkway, Suite 300, Hampton, VA 23666, USA, Tel: +1 757 865 0000, email: cornelius@ama-inc.com 
the trajectory and attitude of the spacecraft carrying a boulder that has been secured by a capture mechanism.

As discussed in Ref. [4], the current design of the ARRM Alternate Concept includes three mechanical legs to contact the surface and stabilize the spacecraft, and provide the liftoff forces necessary to escape the NEA gravity field. In addition, three manipulator arms are used to secure the boulder; in this study we assume that the spacecraft, manipulator arms, and boulder form one composite rigid body during ascent. After the push-off legs leave the surface, RCS jets are used to control the attitude. The capture mechanism is designed to handle a baseline boulder diameter of $4 \mathrm{~m}$, and can accommodate a diameter as small as $0.5 \mathrm{~m}$. The primary goal of the controlled ascent is to depart from the NEA and maintain attitude control throughout the first 10 to $50 \mathrm{~m}$ such that the solar array tips maintain a healthy ground clearance. The wingspan of the spacecraft is approximately $35 \mathrm{~m}$ with the MegaFlex arrays and $51 \mathrm{~m}$ with the Rosa Arrays. In this work, the MegaFlex arrays are considered.

For the purpose of this study, the NEA target is selected to be asteroid 25143 Itokawa, which spins at $12.1324 \mathrm{hrs}$ per revolution, and the landing site is chosen to be in the area of the Muses Sea (Ref. [5]). A three-axis attitude controller is designed to track the local vertical in real time, with the goal of keeping the solar array axes parallel to the ground during the early stage of ascent. This controller is based on the inertia-free linear feedback controller presented in Ref. [6], which is robust to the unknown moment of inertia of the rigid body if the control torque is provided by an actuator that exerts a pure couple, such as a reaction wheel or other momentum exchange device.

The absence of good physical characterizations of the majority of NEAs and their boulders makes controlled ascent a challenging prospect. Little time is available for boulder mass property estimation during the early portion of ascent because it is important to leave the vicinity of the NEA quickly in order to avoid a collision. This paper presents sensitivity analysis of attitude control performance in the presence of uncertainties in the following parameters: boulder size, estimated density, density uncertainty, shapes and orientations of the boulder relative to the spacecraft when captured, the unknown offset of the true center of mass (CM) from the estimated location, and uneven distribution of force among the three push-off legs. The metrics of primary interest are the deviation of the array axis from the local horizontal plane, the ground clearance of the solar array tips, the acceleration experienced at the solar arrays, and the control authority. The results of a large number of numerical simulations show that attitude control performance is most affected by $\mathrm{CM}$ offset and an uneven distribution of push-off forces.

To the best of the authors' knowledge, controlled ascent has not been performed from a celestial body other than the Moon except for an emergency ascent of the Hayabusa spacecraft from Itokawa, which became known only later when data was analyzed (Ref. [5]). No precedent exists for controlled ascent with a payload whose size and mass are comparable to those of the spacecraft, and whose physical characteristics are not well known.

The remainder of this paper is organized as follows. A description of the spacecraft, landing legs, and capture arms is provided in Sec. 2, and an ascent Concept of Operations that is particular to the study is presented in Sec. 3. The sources of uncertainties and the trade space are discussed in Sec. 4, the main results are presented in Sec. 5, and conclusions are given in Sec. 6. 


\section{The Spacecraft}

The spacecraft is shown with a boulder in Figs. 1 and 2. The spacecraft bus is roughly a right hexagonal prism with a mass of 7,600 kg, a height of $4.96 \mathrm{~m}$, and a diameter of $3 \mathrm{~m}$. Two solar arrays are attached to the bus; each has a mass of $200 \mathrm{~kg}$, and a center located $11.805 \mathrm{~m}$ from the centerline of the bus. The spacecraft lands on the asteroid with three legs, which support the spacecraft during its stay on the asteroid's surface. When the spacecraft lands on the asteroid's surface, the legs pads are $3 \mathrm{~m}$ away from the centerline. Each leg consists of multiple articulated truss-structure links. Three similar mechanisms, smaller than the legs, are used to collect the boulder and secure it to the spacecraft prior to ascent and departure from the asteroid's surface. When the boulder is captured, it is held such that the boulder CM is $3.5 \mathrm{~m}$ away from the base of the capture arms. A comprehensive description of the landing legs and capture arms can be found in Ref. [4].

Four pods, each containing four Reaction Control System (RCS) thrusters, are mounted to the bus on struts. The position vector $\mathbf{r}^{B^{*} P_{i}}$ from the mass center of the bus, $B^{*}$, to each of the four pods $P_{i}(i=1,2,3,4)$, and direction of thrust applied by each thruster, are reported in Table 1 in terms of $\hat{\mathbf{b}}_{1}, \hat{\mathbf{b}}_{2}$, and $\hat{\mathbf{b}}_{3}$, a set of right-handed mutually orthogonal unit vectors fixed in the spacecraft bus, directed as shown in Figs. 1 and 2. Each thruster has a specific impulse $I_{\mathrm{sp}}=230 \mathrm{~s}$. The force applied by thrusters $1, \ldots, 4$ has a maximum magnitude of $15.6 \mathrm{~N}$, whereas the force applied by thrusters $5, \ldots, 16$ has a maximum magnitude of $22.2 \mathrm{~N}$.

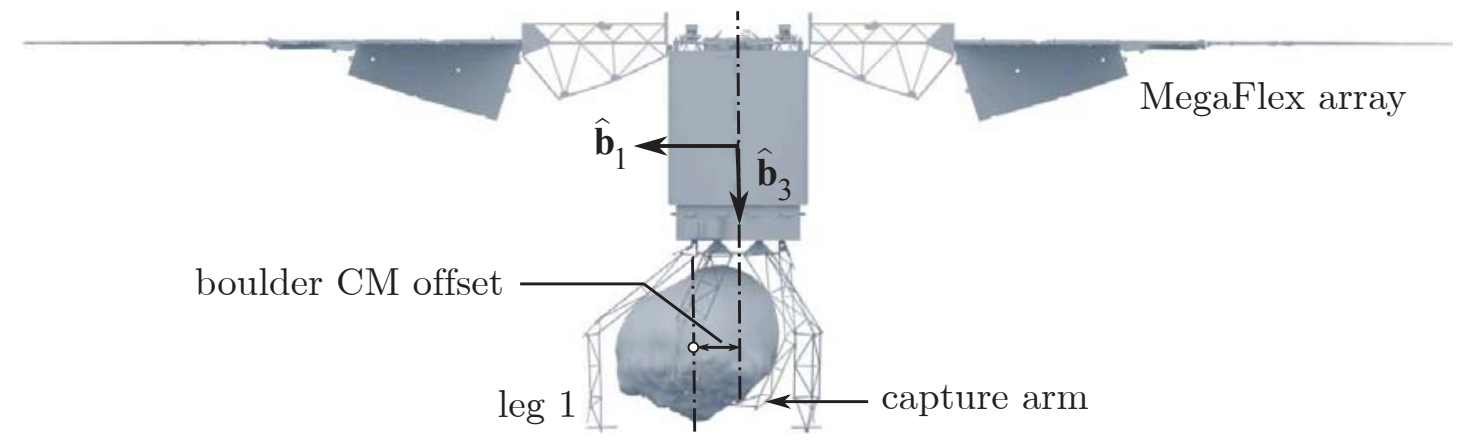

Figure 1: Side view of spacecraft with boulder

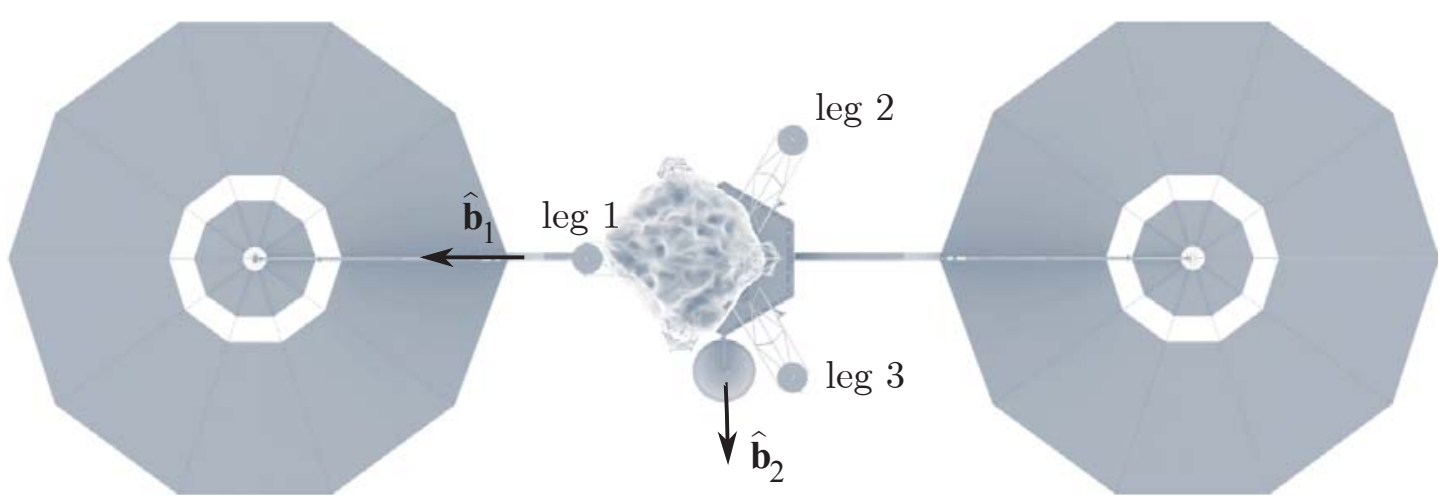

Figure 2: Bottom view of spacecraft with boulder 
Table 1: RCS Thruster Configuration

\begin{tabular}{|c|c|c|c|}
\hline Pod & Position (m) & No. & Thrust Directions \\
\hline \multirow[t]{4}{*}{$P_{1}$} & $\mathbf{r}^{B^{*} P_{1}}=1.5 \hat{\mathbf{b}}_{1}+1.5 \hat{\mathbf{b}}_{2}-2.48 \hat{\mathbf{b}}_{3}$ & 1 & $\hat{\mathbf{b}}_{3}$ \\
\hline & & 5 & $-\hat{\mathbf{b}}_{2}$ \\
\hline & & 9 & $-\frac{1}{\sqrt{2}} \hat{\mathbf{b}}_{1}-\frac{1}{\sqrt{2}} \hat{\mathbf{b}}_{2}$ \\
\hline & & 13 & $-\frac{1}{\sqrt{2}} \hat{\mathbf{b}}_{2}-\frac{1}{\sqrt{2}} \hat{\mathbf{b}}_{3}$ \\
\hline \multirow[t]{4}{*}{$P_{2}$} & $\mathbf{r}^{B^{*} P_{2}}=-1.5 \hat{\mathbf{b}}_{1}+1.5 \hat{\mathbf{b}}_{2}-2.48 \hat{\mathbf{b}}_{3}$ & 2 & $\hat{\mathbf{b}}_{3}$ \\
\hline & & 6 & $-\hat{\mathbf{b}}_{2}$ \\
\hline & & 10 & $\frac{1}{\sqrt{2}} \hat{\mathbf{b}}_{1}-\frac{1}{\sqrt{2}} \hat{\mathbf{b}}_{2}$ \\
\hline & & 14 & $-\frac{1}{\sqrt{2}} \hat{\mathbf{b}}_{2}-\frac{1}{\sqrt{2}} \hat{\mathbf{b}}_{3}$ \\
\hline \multirow[t]{4}{*}{$P_{3}$} & $\mathbf{r}^{B^{*} P_{3}}=-1.5 \hat{\mathbf{b}}_{1}-1.5 \hat{\mathbf{b}}_{2}-2.48 \hat{\mathbf{b}}_{3}$ & 3 & $\hat{\mathbf{b}}_{3}$ \\
\hline & & 7 & $\hat{\mathbf{b}}_{2}$ \\
\hline & & 11 & $\frac{1}{\sqrt{2}} \hat{\mathbf{b}}_{1}+\frac{1}{\sqrt{2}} \hat{\mathbf{b}}_{2}$ \\
\hline & & 15 & $\frac{1}{\sqrt{2}} \hat{\mathbf{b}}_{2}-\frac{1}{\sqrt{2}} \hat{\mathbf{b}}_{3}$ \\
\hline \multirow[t]{4}{*}{$P_{4}$} & $1.5 \hat{\mathbf{b}}_{1}-1.5 \hat{\mathbf{b}}_{2}-2.48 \hat{\mathbf{b}}_{3}$ & 4 & $\hat{\mathbf{b}}_{3}$ \\
\hline & & 8 & $\hat{\mathbf{b}}_{2}$ \\
\hline & & 12 & $-\frac{1}{\sqrt{2}} \hat{\mathbf{b}}_{1}+\frac{1}{\sqrt{2}} \hat{\mathbf{b}}_{2}$ \\
\hline & & 16 & $\frac{1}{\sqrt{2}} \hat{\mathbf{b}}_{2}-\frac{1}{\sqrt{2}} \hat{\mathbf{b}}_{3}$ \\
\hline
\end{tabular}

\section{Ascent Concept of Operations}

The proximity operations of the ARRM Alternate Concept consists of asteroid characterization, dry run attempts, approach, descent, landing, capture, ascent, etc., which are well described in Ref. [7]. For this study of the ascent phase, it is assumed that the landing site is located in the Muses Sea at coordinates $(126.3,76.8,-12.2) \mathrm{m}$ in the body frame of Itokawa [8]. The axis of symmetry of the spacecraft is assumed to be initially aligned with the local vertical. The push-off legs provide a constant force to achieve a $\Delta V=0.2 \mathrm{~m} / \mathrm{s}$ in 10 seconds, which is enough to escape the gravity field of Itokawa. Due to possible uneven surface firmness beneath the three leg pads, or uncertainties in the actuators, the legs may provide uneven push-off forces. The force from each leg is assumed to remain constant throughout the 10 seconds. The uncertainties in boulder mass properties and CM position, together with uneven push-off forces, can lead to a disturbance torque that causes the solar arrays tip away from local horizontal and dip towards the surface. This can happen at the very beginning of the ascent; therefore, the attitude controller is engaged at all times, with the commanded torque supplied by the RCS thrusters. In addition, it is assumed that the cohesive force that keeps the boulder attached to the asteroid is already broken prior to this part of the analysis, and the dynamics of liberating the boulder is not considered.

In order to avoid pluming the NEA surface and stirring up dust that may contaminate the 
spacecraft, thrusters 13,14, 15 and 16 are not used during the first $20 \mathrm{~m}$ of ascent. In addition, mission requirements state that the ground clearance of the solar arrays must be above $5 \mathrm{~m}$, and the acceleration at the tips of the arrays must be less than $0.1 \mathrm{~g}$.

\section{The Sources of Uncertainties and Trade Space}

Major challenges to the success of the mission are presented by a number of uncertainties during the initial stage of ascent, including the mass properties of the boulder, the unknown characteristics of the landing surface, navigation errors, unevenly distributed push-off forces, and CM offset that can be caused by a number of factors. All of these parameters greatly affect the performance of the controller designed to maintain an upright posture of the composite body, and effects of parameter variations are studied in this paper. The parameters of interest are boulder size, boulder density, boulder density uncertainty, boulder shape, boulder orientation relative to the array axis, CM offsets, and push-off force distribution. The total number of cases in the trade space is 8100 . The uncertainties assumed in this study are now described and quantified.

Several combinations of boulder size and shape are studied. Three shapes are considered, namely a sphere, a 211 ellipsoid, and a 221 ellipsoid. Ratios of diameter lengths are indicated in the numerical designations of the ellipsoids. For each shape, three sizes are considered, corresponding to a spherical boulder diameter $d$ of $4 \mathrm{~m}, 3 \mathrm{~m}$, and $2 \mathrm{~m}$. The diameters of the two ellipsoids are determined by assuming that the ellipsoid has the same mass as the sphere with a given diameter. The semi-diameters of the 211 and 221 ellipsoids are listed in Table 2.

Table 2: Semi-diameters $a, b, c,(\mathrm{~m})$ of the considered boulders

\begin{tabular}{c|l|l|l|l|l|l|l|l|l}
\hline \multirow{2}{*}{ Size } & \multicolumn{3}{|c|}{ Sphere } & \multicolumn{3}{c|}{ 211 Ellipsoid } & \multicolumn{3}{c}{ 221 Ellipsoid } \\
\cline { 2 - 10 } & $a$ & $b$ & $c$ & $a$ & $b$ & $c$ & $a$ & $b$ & $c$ \\
\hline \hline$d=4 \mathrm{~m}$ & 2 & 2 & 2 & 3.17 & 1.59 & 1.59 & 2.52 & 2.52 & 1.26 \\
\hline$d=3 \mathrm{~m}$ & 1.5 & 1.5 & 1.5 & 2.38 & 1.19 & 1.19 & 1.89 & 1.89 & 0.94 \\
\hline$d=2 \mathrm{~m}$ & 1 & 1 & 1 & 1.59 & 0.79 & 0.79 & 1.26 & 1.26 & 0.63 \\
\hline
\end{tabular}

In the case of the 221 ellipsoid, it is assumed that the boulder sits on the surface with its short axis perpendicular to the surface. When the boulder is a 211 ellipsoid, it is assumed that the boulder lies on the surface with its long axis parallel to the surface. For the 211 ellipsoidal boulder, two orientations of the long axis are considered: parallel and perpendicular to the solar array axis.

It is assumed that a good shape model of the boulder can be established prior to the capture during the characterization phase and dry runs to the candidate target sites. It is also assumed that the boulder is coherent and that there is no significant variation in the density throughout the boulder. Based on these assumptions, the center of mass and the moment of inertia of the boulder can be calculated, provided the density of the boulder can be estimated. In this study, it is assumed that the boulder density can be estimated to within $\pm 10 \%$ of the true density. Three values of density are considered, namely, 3.0, 2.5, and $2.0 \mathrm{~g} / \mathrm{cc}$. For each value, the true density is considered to be $10 \%$ less than, the same as, or $10 \%$ more than the estimated density. The 
Table 3: Composite body vertical CM offset ( $\mathrm{mm}$ ) along $\hat{\mathbf{b}}_{3}$ axis (relative to the estimated position) due to density variation

\begin{tabular}{c|r|r|r|r|r|r}
\hline Est. density & \multicolumn{2}{|c|}{$2.0 \mathrm{~g} / \mathrm{cc}$} & \multicolumn{2}{c|}{$2.5 \mathrm{~g} / \mathrm{cc}$} & \multicolumn{2}{c}{$3.0 \mathrm{~g} / \mathrm{cc}$} \\
\hline True density & $-10 \%$ & $+10 \%$ & $-10 \%$ & $+10 \%$ & $-10 \%$ & $+10 \%$ \\
\hline \hline$d=4 \mathrm{~m}$ & -6.3 & 5.2 & -5.2 & 4.4 & -4.5 & 3.7 \\
\hline$d=3 \mathrm{~m}$ & -11.1 & 9.5 & -9.8 & 8.3 & -8.7 & 7.4 \\
\hline$d=2 \mathrm{~m}$ & -15.7 & 14.2 & -15.6 & 13.9 & -15.1 & 13.4 \\
\hline
\end{tabular}

Table 4: Boulder masses (ton) considered in the trade space

\begin{tabular}{c|c|c|c|c}
\hline Diameter & $2.0 \mathrm{~g} / \mathrm{cc}$ & $2.5 \mathrm{~g} / \mathrm{cc}$ & $3.0 \mathrm{~g} / \mathrm{cc}$ & s/c mass \\
\hline \hline$d=4 \mathrm{~m}$ & 67.0 & 83.8 & 100.5 & \multirow{2}{*}{8} \\
\cline { 1 - 4 }$d=3 \mathrm{~m}$ & 28.3 & 35.3 & 42.4 & \multirow{2}{*}{8} \\
\cline { 1 - 4 }$d=2 \mathrm{~m}$ & 8.4 & 10.5 & 12.6 & \\
\hline
\end{tabular}

uncertainties in the density estimation affect not only the moment of inertia of the boulder, but also the mass of the boulder, which consequently causes uncertainties in the location of the CM of the composite body.

For spherical boulders, the effects of variations in diameter and density on the offset of the combined CM (true CM relative to the estimated CM) in the direction of $\hat{\mathbf{b}}_{3}$ are recorded in Table 3. It can be seen that the vertical CM offset increases when the boulder gets smaller and lighter, and up to $16 \mathrm{~mm}$ of vertical CM offset can be expected for the smallest boulder considered. The $\mathrm{CM}$ offset affects the knowledge of the combined moment of inertia and the accuracy of the torque delivered by the RCS thrusters.

With the boulder sizes and densities, the boulder mass ranges from being comparable to the spacecraft mass to up to two orders of magnitude heavier. The boulder mass for the cases considered in this study as well as the spacecraft mass are shown in Table 4.

The spacecraft uses three supporting legs to provide the push-off force needed to achieve an escape velocity of $0.2 \mathrm{~m} / \mathrm{s}$ off the surface of Itokawa. However, unknown surface characteristics as well as uncertainties in the push-off actuators themselves can contribute to uneven distribution of push-off forces among the three legs. Five force distributions considered in this study are listed in Table 5.

When the spacecraft touches down on the surface, its axis of symmetry may not be accurately aligned with the $\mathrm{CM}$ of the boulder due to navigation errors during the descent. The position error of the onboard sensors is taken to be $0.5 \mathrm{~m}, 3 \sigma$. This contributes to the knowledge errors of the true CM location of the composite body. In this study, the sensitivity of the ascent performance with respect to the $\mathrm{CM}$ offset is investigated, and the trade space includes boulder $\mathrm{CM}$ offsets of $0.5 \mathrm{~m}$ in the 15 directions listed in Table 6 . 
Table 5: Push-off force distributions among three legs

\begin{tabular}{c|c|c|c}
\hline Index & leg 1 & leg 2 & leg 3 \\
\hline \hline 1 & \multicolumn{3}{|c}{ Even distribution } \\
\hline 2 & $30 \%$ & $40 \%$ & $30 \%$ \\
\hline 3 & $40 \%$ & $30 \%$ & $30 \%$ \\
\hline 4 & $25 \%$ & $50 \%$ & $25 \%$ \\
\hline 5 & $50 \%$ & $25 \%$ & $25 \%$ \\
\hline
\end{tabular}

Table 6: Location of true boulder CM relative to estimated $\mathrm{CM}$ in the trade space (unit $=\mathrm{m}$ )

\begin{tabular}{c|c}
\hline Index & CM offsets \\
\hline \hline 1 & no offset \\
2 & $\frac{1}{2} \hat{\mathbf{b}}_{1}$ \\
3 & $-\frac{1}{2} \hat{\mathbf{b}}_{1}$ \\
4 & $\frac{1}{2} \hat{\mathbf{b}}_{2}$ \\
5 & $-\frac{1}{2} \hat{\mathbf{b}}_{2}$ \\
6 & $\frac{1}{2} \hat{\mathbf{b}}_{3}$ \\
7 & $-\frac{1}{2} \hat{\mathbf{b}}_{1}$ \\
8 & $\frac{\sqrt{3}}{6} \hat{\mathbf{b}}_{1}+\frac{\sqrt{3}}{6} \hat{\mathbf{b}}_{2}+\frac{\sqrt{3}}{6} \mathbf{b}_{3}$ \\
9 & $\frac{\sqrt{3}}{6} \hat{\mathbf{b}}_{1}-\frac{\sqrt{3}}{6} \hat{\mathbf{b}}_{2}+\frac{\sqrt{3}}{6} \mathbf{b}_{3}$ \\
10 & $-\frac{\sqrt{3}}{6} \hat{\mathbf{b}}_{1}-\frac{\sqrt{3}}{6} \hat{\mathbf{b}}_{2}+\frac{\sqrt{3}}{6} \mathbf{b}_{3}$ \\
11 & $-\frac{\sqrt{3}}{6} \hat{\mathbf{b}}_{1}+\frac{\sqrt{3}}{6} \hat{\mathbf{b}}_{2}+\frac{\sqrt{3}}{6} \mathbf{b}_{3}$ \\
12 & $\frac{\sqrt{3}}{6} \hat{\mathbf{b}}_{1}+\frac{\sqrt{3}}{6} \hat{\mathbf{b}}_{2}-\frac{\sqrt{3}}{6} \mathbf{b}_{3}$ \\
13 & $\frac{\sqrt{3}}{6} \hat{\mathbf{b}}_{1}-\frac{\sqrt{3}}{6} \hat{\mathbf{b}}_{2}-\frac{\sqrt{3}}{6} \mathbf{b}_{3}$ \\
14 & $-\frac{\sqrt{3}}{6} \hat{\mathbf{b}}_{1}-\frac{\sqrt{3}}{6} \hat{\mathbf{b}}_{2}-\frac{\sqrt{3}}{6} \mathbf{b}_{3}$ \\
15 & $-\frac{\sqrt{3}}{6} \hat{\mathbf{b}}_{1}+\frac{\sqrt{3}}{6} \hat{\mathbf{b}}_{2}-\frac{\sqrt{3}}{6} \mathbf{b}_{3}$ \\
\hline
\end{tabular}




\section{Results}

This section summarizes the results of the sensitivity trade study. A polyhedral gravity model [9] based on a shape model consisting of of 25,350 vertices and 49,152 facets is used for Itokawa. Since the force supplied by the push-off legs is much greater than that due to the solar radiation pressure, the effect of the solar radiation is neglected.

A three-axis attitude controller is used to align the spacecraft axis of symmetry with the local vertical. It is based on the linear quaternion feedback controller presented in Ref. [6]. This approach is chosen because the controller does not rely on the knowledge of the moments of inertia of the rigid body, and it is thus an inertia-free feedback control law. If the spacecraft is equipped with a torque actuator (an actuator that applies a pure couple), then the controller is robust to the uncertainties in the mass properties of the rigid body, provided enough control authority is available. In the present case the control torque is provided by the RCS thrusters and appropriate thrusters are selected to deliver the commanded torque. However, the thruster selection is based on the estimated location of the $\mathrm{CM}$ of the combined body. Thus, the actual torque delivered by the selected thrusters will be different from the commanded torque because of the uncertainties in the knowledge of the system CM.

The knowledge of the spacecraft attitude and angular rate is provided by the onboard navigation system, which is not perfect. In this study, the standard deviation for the attitude error is assumed to be $0.01 \mathrm{deg}(36 \mathrm{arcsec}$ ), and the standard deviation for the angular rate error is assumed to be $1 / 100$ of the Itokawa spin rate $\left(1.4 \times 10^{-6} \mathrm{rad} / \mathrm{s}\right)$.

\subsection{The boulder size and density}

The effect of the uncertainties in the trade space greatly varies with the size and density of the boulder. The larger and heavier the boulder is, the harder it is in general to control the composite body in the presence of perturbations. For the boulder diameters and densities considered, the maximum angles between the solar array axis and and local horizontal plane are listed in Table 7 , and the minimum ground clearances of the solar array tips are shown in Table 8. As can be seen in the tables, as the size or density of the boulder increases, the solar array experiences larger deviations from the local horizontal plane, resulting in smaller ground clearances.

Table 7: Maximum deviation (deg) of the array axis from the local horizonal plane

\begin{tabular}{c|r|r|r}
\hline \multirow{2}{*}{ Diameter } & \multicolumn{3}{|c}{ density } \\
\cline { 2 - 4 } & $2 \mathrm{~g} / \mathrm{cc}$ & $2.5 \mathrm{~g} / \mathrm{cc}$ & $3 \mathrm{~g} / \mathrm{cc}$ \\
\hline \hline $2 \mathrm{~m}$ & 3.05 & 3.82 & 4.73 \\
\hline $3 \mathrm{~m}$ & 15.74 & 23.07 & 30.49 \\
\hline $4 \mathrm{~m}$ & 66.56 & 89.94 & 89.72 \\
\hline
\end{tabular}

For a boulder of $4 \mathrm{~m}$ in diameter and all three values of density, in the worst case of trade space the solar arrays hit the ground while ascending as indicated by the negative ground clearances in Table 8. Table 7 shows that the spacecraft can tip over so much that the solar array axis is almost 
Table 8: Minimum ground clearance $(\mathrm{m})$ of the array tips

\begin{tabular}{c|r|r|r}
\hline \multirow{2}{*}{ Diameter } & \multicolumn{3}{|c}{ density } \\
\cline { 2 - 4 } & $2 \mathrm{~g} / \mathrm{cc}$ & $2.5 \mathrm{~g} / \mathrm{cc}$ & $3 \mathrm{~g} / \mathrm{cc}$ \\
\hline \hline $2 \mathrm{~m}$ & 9.52 & 9.51 & 9.50 \\
\hline $3 \mathrm{~m}$ & 8.29 & 6.94 & 5.13 \\
\hline $4 \mathrm{~m}$ & -1.91 & -6.41 & -9.05 \\
\hline
\end{tabular}

perpendicular to the surface. The situation improves greatly when the boulder diameter reduces to $3 \mathrm{~m}$. In this case, even though the solar arrays deviates from the local horizontal plane up to 30.49 degrees in the worst case, the ground clearance of the array tip is above $5 \mathrm{~m}$, which is acceptable in terms of performance. It should be noted here that as the diameter, and hence the mass, of the boulder increases, the force per leg increases to achieve the $0.2-\mathrm{m} / \mathrm{s}$ escape velocity in 10 seconds. Thus, the total disturbance torque applied to the system as a result of uneven push-off force distribution grows as the boulder becomes bigger and heavier, while the RCS thrusters are kept at the same level.

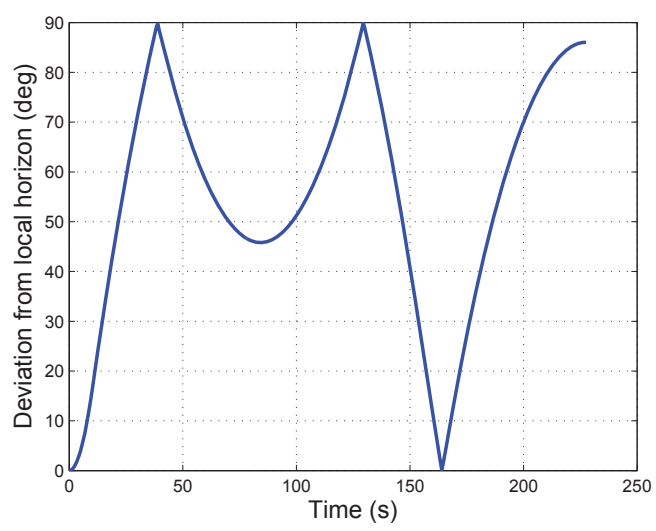

Figure 3: The deviation of the solar array axis from the local horizontal for the case with the worst ground clearance with a 4-m diameter boulder.

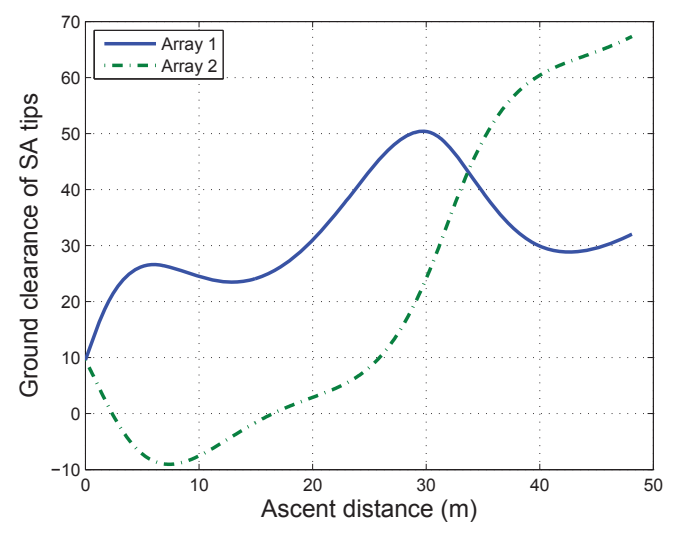

Figure 4: The worst-case ground clearance of the solar arrays with a 4-m diameter boulder.

For the case of a 4-m diameter boulder, the deviation of the array axis from the local horizontal, ground clearance of the arrays, and the control torque for the case with the worst ground clearance are shown in Figs. 3-5. With a $\Delta V=0.2 \mathrm{~m} / \mathrm{s}$ achieved within 10 seconds, it takes about 227.5 seconds for the combined body to ascend to a 50-m altitude. Figure 3 indicates that the solar arrays tip past the local vertical, and does not level out throughout the 50-m ascent. Figure 4 shows that one of the arrays hits the surface when the combined body is at an altitude of $7.5 \mathrm{~m}$, about $37.5 \mathrm{~s}$ after the start of the ascent. Figure 5 shows that in this case, the commanded torque is significantly greater than the torque that can be delivered by the RCS thrusters, causing the system to be severely underactuated. 


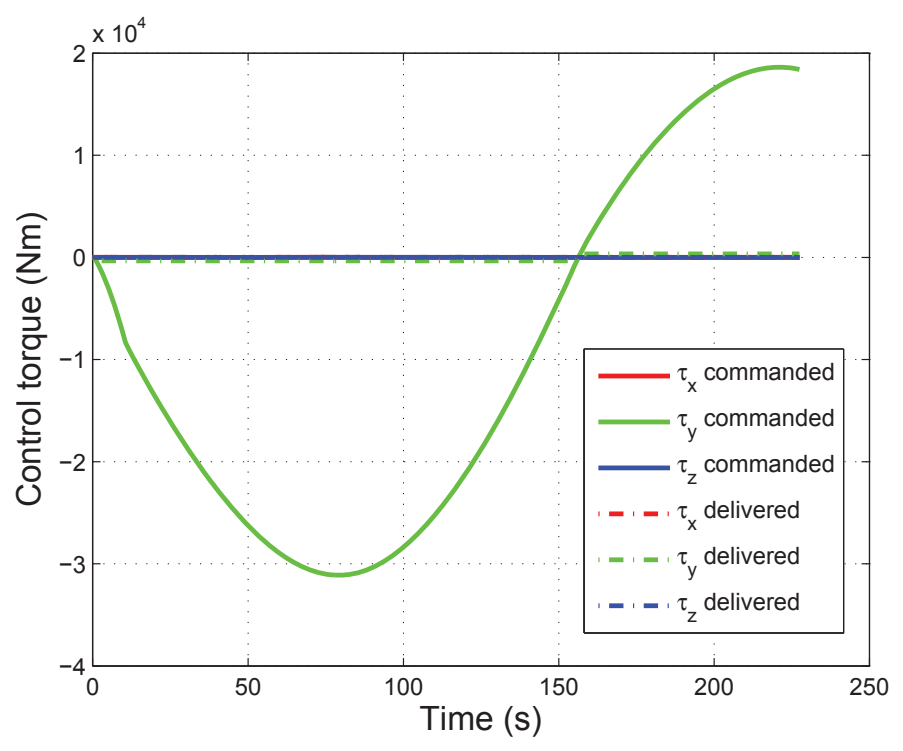

Figure 5: The control torque profile for the case with the worst ground clearance with a 4-m diameter boulder.

For the case of a 3-m diameter boulder, the deviation of the array axis from the local horizontal, ground clearance of the arrays, and the control torque for the case with the worst ground clearance are shown in Figs. 6-8. Figure 6 indicates that the solar arrays are leveled out about $150 \mathrm{~s}$ into the ascent, at which time an altitude of approximately $30 \mathrm{~m}$ is reached. During the ascent, the spacecraft tips over while leaving the surface, so the deviation from the local horizontal plane is not the only indicator of the array ground clearance. In fact, Fig. 6 indicates that the maximum deviation angle occurs around $40 \mathrm{~s}$, or $8 \mathrm{~m}$ altitude, but Fig. 7 shows that the arrays are closest to the ground at about $5 \mathrm{~m}$ in altitude, or about $25 \mathrm{~s}$ after the start of the ascent. Figure 8 shows that in this case, the commanded torque is significantly greater than the torque that can be delivered by the RCS thrusters. Nonetheless, the RCS thrusters have enough control authority to keep the arrays off the ground by at least $5 \mathrm{~m}$ in this case.

If the boulder is $2 \mathrm{~m}$ in diameter, then the worst case deviation of the solar array axis from the local horizontal plane is less than $5 \mathrm{deg}$, with a minimum ground clearance of $9.5 \mathrm{~m}$, as shown in Tables 7 and 8. Notice that the arrays have a ground clearance of $9.52 \mathrm{~m}$ when the spacecraft is on the ground. Thus, in the worst case, the arrays only dip $20 \mathrm{~mm}$ below the initial level, which leaves a safety margin of $4.5 \mathrm{~m}$. For the case of a 2-m diameter boulder, the deviation of the array axis from the local horizontal, ground clearance of the arrays, and the control torque corresponding to the case with the worst array ground clearance are shown in Figs. 9-11. Figure 9 indicates that the solar arrays are essentially leveled out about $60 \mathrm{~s}$ into the ascent, at which time an altitude of about $12 \mathrm{~m}$ is reached. Figure 11 shows that in this case, the commanded torque can be 2.5 times greater than the torque that can be delivered by the RCS thrusters. Nonetheless, the RCS thrusters have enough control authority to keep the arrays off the ground by $5 \mathrm{~m}$ with a healthy margin. 


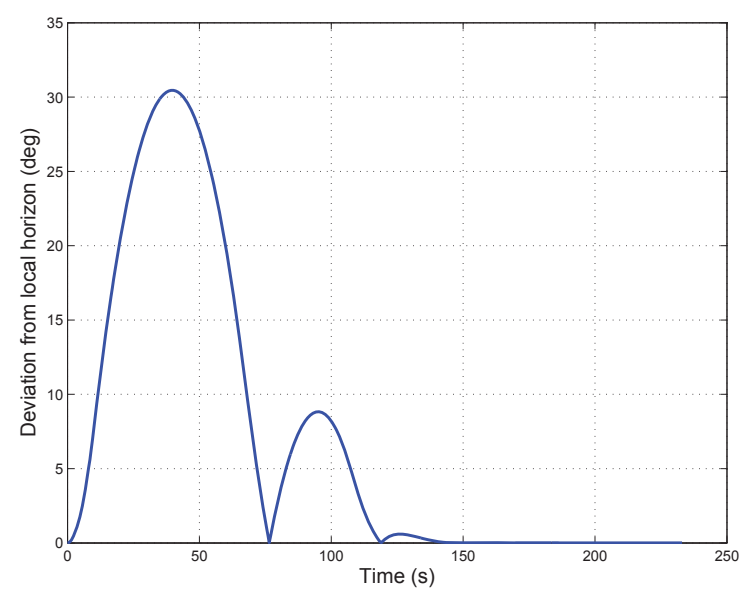

Figure 6: The deviation of the solar array axis from the local horizontal for the case with the worst ground clearance with a 3-m diameter boulder.

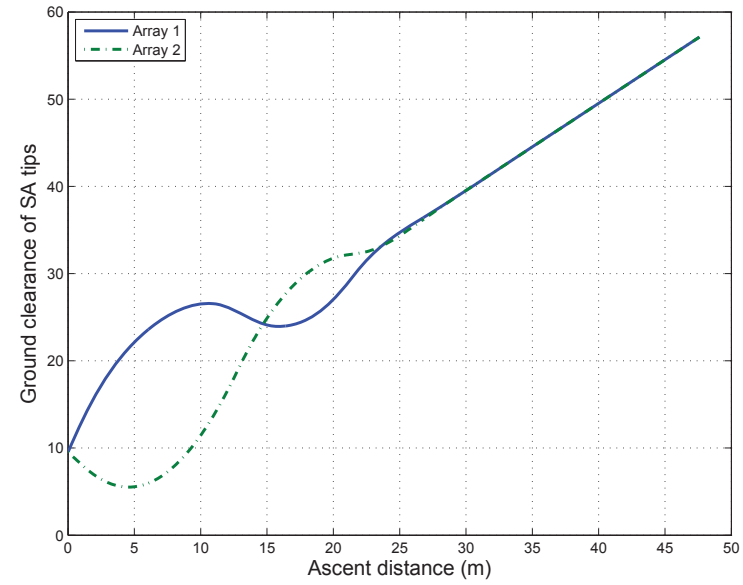

Figure 7: The worst-case ground clearance of the solar arrays with a 3-m diameter boulder.

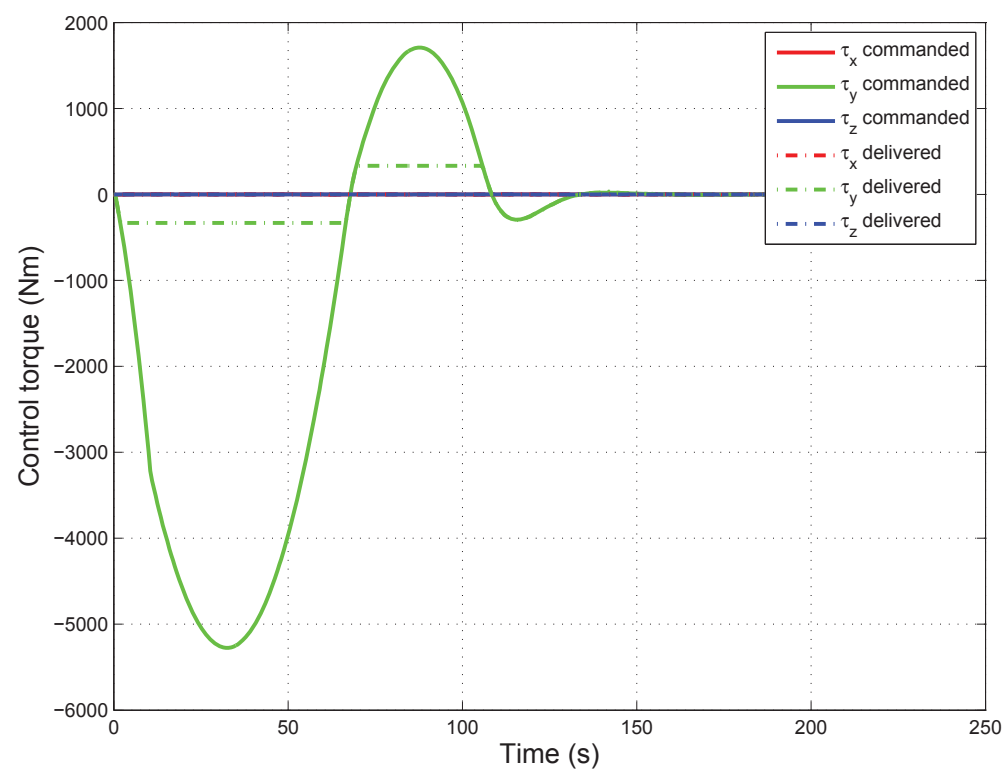

Figure 8: The control torque profile for the case with the worst ground clearance with a 3-m diameter boulder.

\subsection{Boulder shape and orientation}

Boulder shape affects the moments of inertia of the combined body, which significantly influences the attitude control performance. Table 9 lists the principal moments of inertia of 4-m diameter boulders with a density of $3 \mathrm{~g} / \mathrm{cc}$ in the shapes considered. It can be seen that $I_{11}$ and $I_{22}$ for the spherical and 221 ellipsoidal shapes are virtually the same (less than $0.8 \%$ different), and only $I_{33}$ is significantly different. Since it is predominantly $I_{11}$ and $I_{22}$ that affect the control of the array axis orientation, it can be expected that the array ground clearances do not vary much when a 


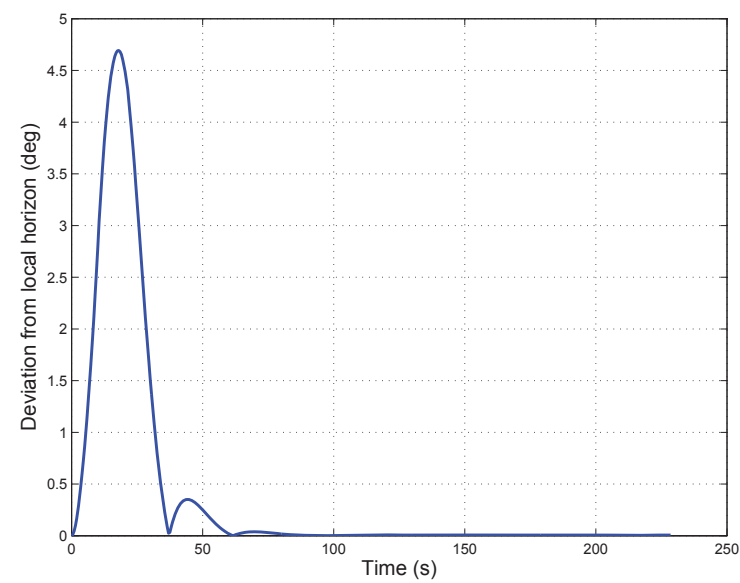

Figure 9: The deviation of the solar array axis from the local horizontal for the case with the worst ground clearance with a 2-m diameter boulder.

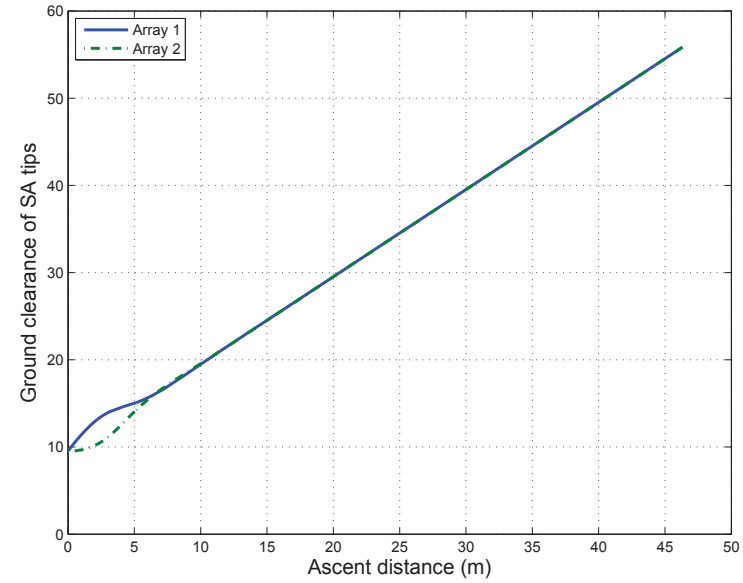

Figure 10: The worst-case ground clearance of the solar arrays with a 2-m diameter boulder.

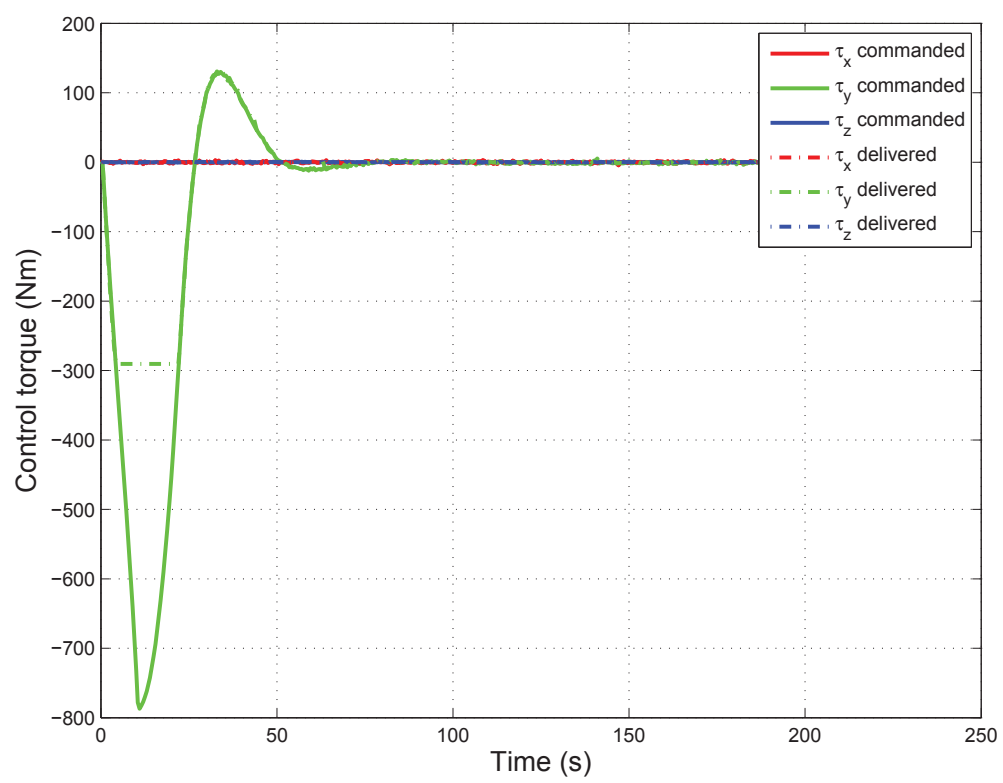

Figure 11: The control torque profile for the case with the worst ground clearance with a 2-m diameter boulder.

boulder assumes a spherical shape or a 221 ellipsoidal shape. In fact, the results show that array ground clearances for a spherical boulder and a 221 ellipsoidal boulder differ by no more than 20 mm. In addition, in the case of a spherical boulder and a 221 ellipsoidal boulder with the short axis perpendicular to the surface, the relative orientation about the axis of symmetry between the spacecraft and boulder is irrelevant.

The principal moments of inertia are significantly different between a sphere and an equivalent 211 ellipsoid with the same mass, resulting in vastly different performances. Figure 12 shows the comparison of the array ground clearances for a spherical boulder, a 211 ellipsoidal boulder with 
its long axis parallel to the array axis, and a 211 ellipsoidal boulder with its long axis perpendicular to the array axis. For the cases shown, the boulder diameter is $4 \mathrm{~m}$, the estimated density is $3 \mathrm{~g} / \mathrm{cc}$, and the true density is $3.3 \mathrm{~g} / \mathrm{cc}$. It can be seen from the figure that for all combinations of CM offset and push-off force distributions, the case of the 211 ellipsoidal boulder with its long axis parallel to the array axis has the greatest array ground clearances, followed by the case of the spherical boulder, and the case of the 211 ellipsoidal boulder with its long axis perpendicular to the array axis has the smallest array ground clearances.

This result can be explained by comparing the moments of inertia of the combined body about the $\hat{\mathbf{b}}_{2}$ axis, which is perpendicular to the array axis. It is clear that the combined moment of inertia about the $\hat{\mathbf{b}}_{2}$ axis is the smallest for a 211 ellipsoidal boulder with its long axis perpendicular to the array axis, and the greatest for the same boulder when its long axis is parallel to the array axis. A greater moment of inertia about $\hat{\mathbf{b}}_{2}$ axis results in a slower response given the same disturbance torque, and consequently greater array ground clearance compared to a smaller moment of inertia about the $\hat{\mathbf{b}}_{2}$ axis.

Table 9: Principal moments of inertia $\left(\mathrm{kg}-\mathrm{m}^{2}\right)$ of 4-m diameter boulders with density of $3 \mathrm{~g} / \mathrm{cc}$ of various shapes

\begin{tabular}{c|c|c|c}
\hline Shapes & $I_{11}$ & $I_{22}$ & $I_{33}$ \\
\hline \hline Sphere & $1.61 \times 10^{5}$ & $1.61 \times 10^{5}$ & $1.61 \times 10^{5}$ \\
\hline 221 ellipsoid & $1.60 \times 10^{5}$ & $1.60 \times 10^{5}$ & $2.55 \times 10^{5}$ \\
\hline 211 ellipsoid & $1.01 \times 10^{5}$ & $2.53 \times 10^{5}$ & $2.53 \times 10^{5}$ \\
\hline
\end{tabular}

\subsection{Density uncertainty}

Uncertainty in density estimation determines whether the real boulder is heavier or lighter than the estimated value. It affects not only the accuracy of the estimate of the moment of inertia of the composite body, but also the location of the combined CM, which in turn affects the accuracy of the torque supplied by the RCS thrusters. Figure 13 shows the array ground clearances for different density estimate uncertainties and combinations of CM offsets and push-off force distributions. This is the case corresponding to a 4-m 211 ellipsoidal boulder with its long axis perpendicular to the array axis and an estimated density of $3 \mathrm{~g} / \mathrm{cc}$. It can be seen that for all $\mathrm{CM}$ offsets and push-off force distributions, a true density greater than the estimated density results in a decrease of the ground clearance of the arrays, and the opposite is true if the true density is smaller than the estimated density. This trend holds true for all other combinations of boulder size, shape, orientation, and density.

The maximum differences in array ground clearances between the cases with density uncertainties and the cases with no density uncertainties for the five assumed push-off force distributions are shown in Table 10. It can be seen that the effect of density uncertainty is most prominent in the cases of more extreme uneven push-off distribution (50\%-25\%-25\%), and less so in the even push-off cases. A density uncertainty of $10 \%$ can result in up to $2 \mathrm{~m}$ of ground clearance difference 

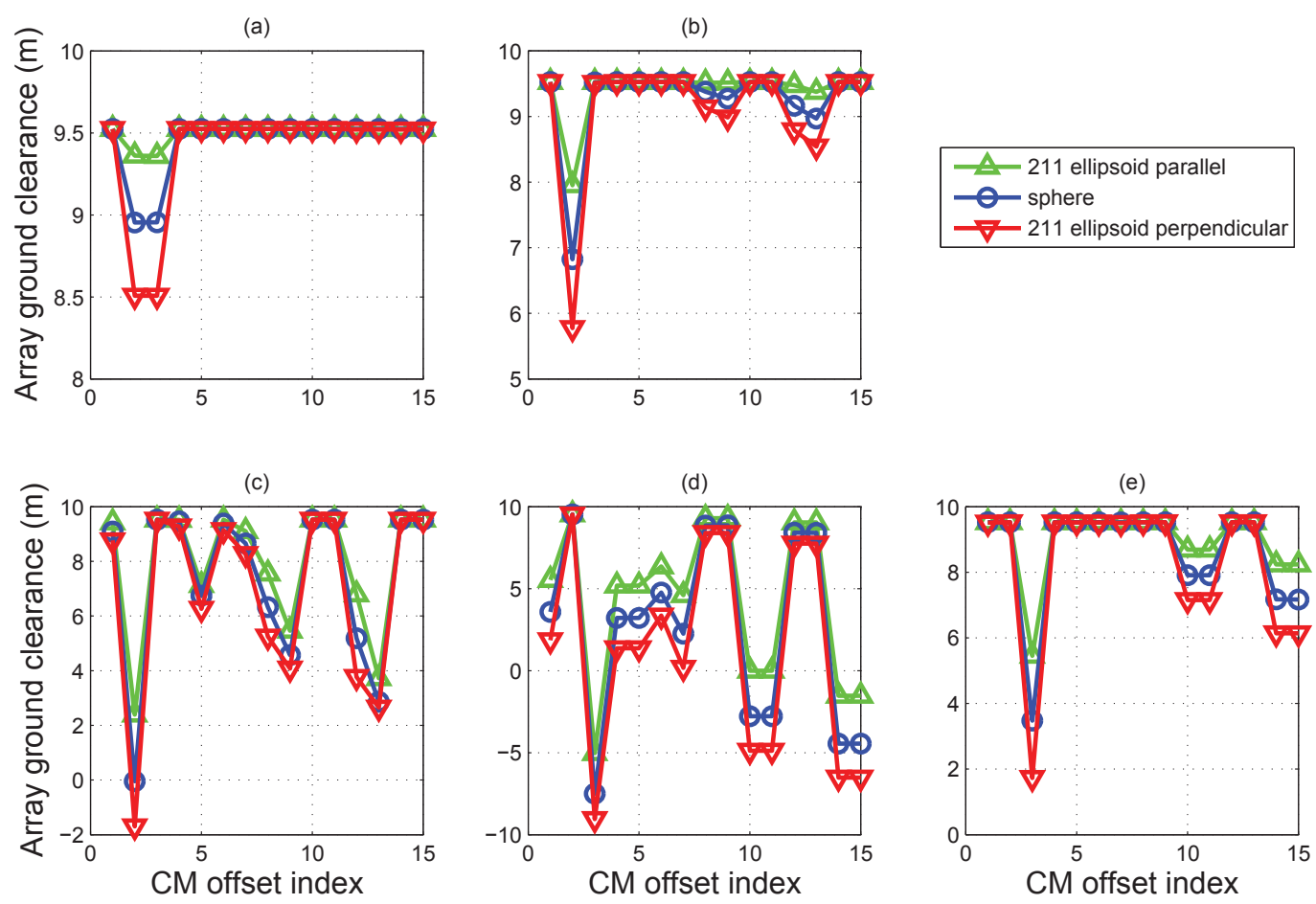

Figure 12: The array ground clearances for a 4-m diameter boulder with density $3 \mathrm{~g} / \mathrm{cc}$ in different shapes and orientations. (a) even push-off, (b) 30\%-40\%-30\%, (c) 25\%-50\%-25\%, (d) 50\%-25\%$25 \%$, (e) $40 \%-30 \%-30 \%$.

in the presence of uneven push-off force distribution. This data clearly shows that overestimating the density results in greater array ground clearance than underestimating the density.

\subsection{CM offset and uneven push-off force distribution}

The greatest contribution to the off-nominal performance of the spacecraft ascent is undoubtedly from the combination of the CM offset and the uneven push-off force distribution. CM offset contributes to the uncertainty in the estimation of the true moment of inertia and the torques delivered by the RCS thrusters, while the uneven push-off force distribution contributes to the attitude disturbance during the push-off. The worst-case array ground clearances for the combinations of CM offsets and push-off force distributions are shown in Fig. 14. This corresponds to the case involving a 4-m 211 ellipsoidal boulder with its long axis perpendicular to the array axis, an estimated density of $3 \mathrm{~g} / \mathrm{cc}$, and a true density of $3.3 \mathrm{~g} / \mathrm{cc}$.

It can be seen that in the case of an even push-off, the minimum array ground clearance is $8.4 \mathrm{~m}$ among all $\mathrm{CM}$ offsets, with a healthy $3.4 \mathrm{~m}$ margin above the $5-\mathrm{m}$ safety array clearance requirement. On the other hand, in the event of no $\mathrm{CM}$ offset $(\mathrm{CM}$ offset index $=1)$, all uneven push-off force distributions except 50\%-25\%-25\% provide at least a $3.7 \mathrm{~m}$ margin above the 5-m clearance requirement. In the case that is the exception, the array clearance is $1.9 \mathrm{~m}$ and below the requirement of $5 \mathrm{~m}$. 

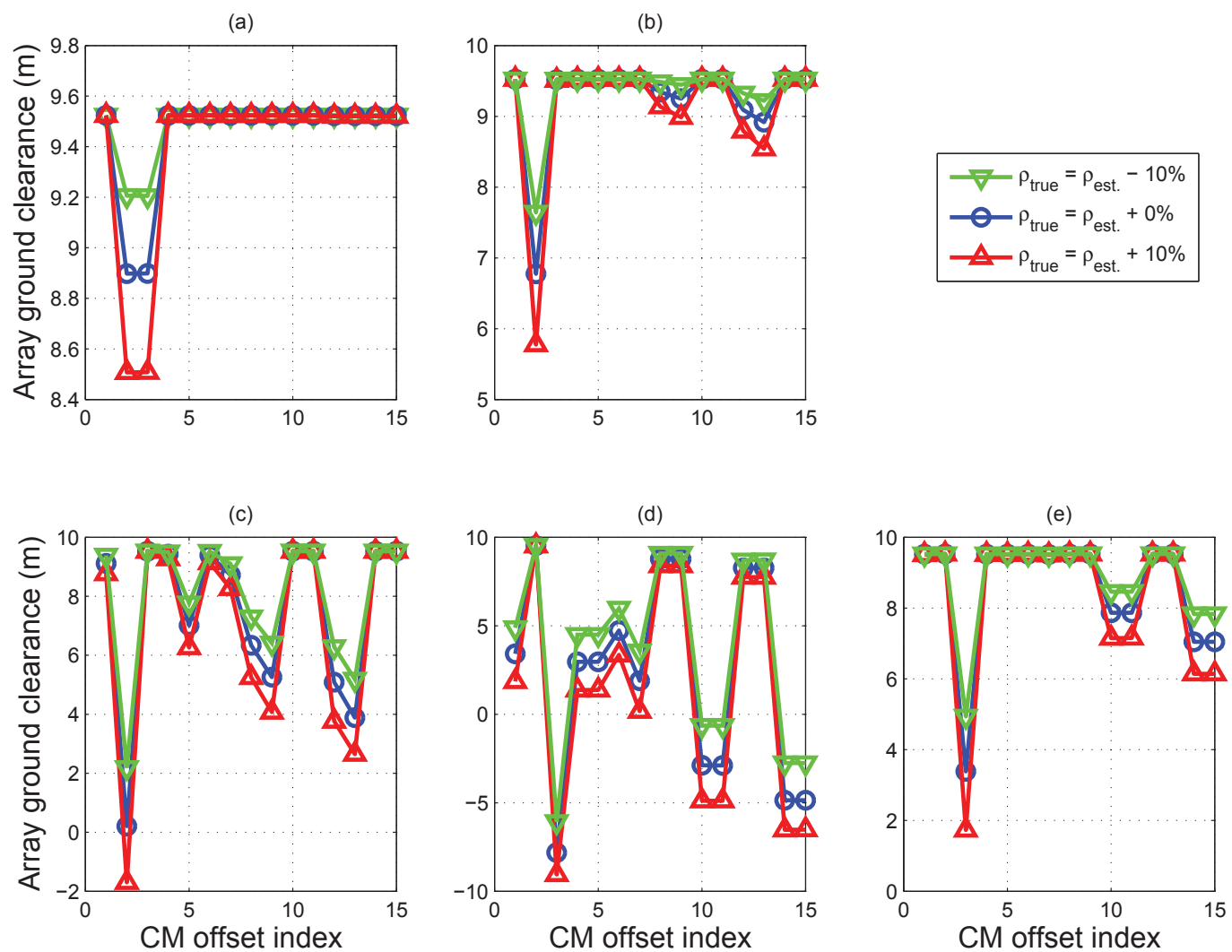

Figure 13: The array ground clearances for a 4-m diameter boulder with density $3 \mathrm{~g} / \mathrm{cc}$ with different density uncertainties. (a) even push-off, (b) 30\%-40\%-30\%, (c) $25 \%-50 \%-25 \%$, (d) $50 \%$ $25 \%-25 \%$, (e) $40 \%-30 \%-30 \%$.

It is observed from Fig. 14 that for push-off force distribution of 30\%-40\%-30\%, ground clearances for all cases of CM offsets are above $5 \mathrm{~m}$, with the worst case array ground clearance at 5.82 $\mathrm{m}$, a healthy margin of $0.82 \mathrm{~m}$ above the requirement. When leg 1 supplies $40 \%$ of the push-off forces, as in the case of 40\%-30\%-30\%, the arrays on all but one occasion have ground clearance above $5 \mathrm{~m}$ with at least a 1-m margin. The exceptional case has a ground clearance of $1.7 \mathrm{~m}$.

Unsurprisingly, worse ground clearances are observed when the push-off forces are distributed more unevenly. If the push-off force is distributed $25 \%-50 \%-25 \%$ between the three legs, the array tips dip below $5 \mathrm{~m}$ to the surface in four occasions of CM offsets. When the push-off force distribution becomes 50\%-25\%-25\%, all but five CM offsets result in array ground clearances less than $5 \mathrm{~m}$. In five occasions, the arrays hit the ground. It should be noted that the worst ground clearance is observed when the true CM is located at $-0.5 \hat{\mathbf{b}}_{1}$, and the leg 1 supplies $50 \%$ of the push-off force. In this case the true CM and the leg that supplies the largest push-off force are located on opposite sides of the spacecraft axis of symmetry, resulting in the maximum disturbance torque during push-off.

The worst case in the trade space in terms of array ground clearance consists of trade parameters listed in Table 11. For this case, the accelerations experienced at the solar array tips are shown in 
Table 10: Maximum difference in ground clearance $(\mathrm{m})$ between the cases with uncertain densities and the cases with nominal density

\begin{tabular}{r|c|c|c|c|c}
\hline \multirow{2}{*}{$\begin{array}{c}\text { True } \\
\text { density }\end{array}$} & \multicolumn{5}{|c}{ Push-off force distribution (\%) } \\
\cline { 2 - 6 } & even push-off & $30-40-30$ & $25-50-25$ & $50-25-25$ & $40-30-30$ \\
\hline \hline$-10 \%$ & 0.20 & 0.65 & 1.75 & 1.98 & 1.22 \\
\hline$+10 \%$ & -0.25 & -0.75 & -1.76 & -1.86 & -1.32 \\
\hline
\end{tabular}

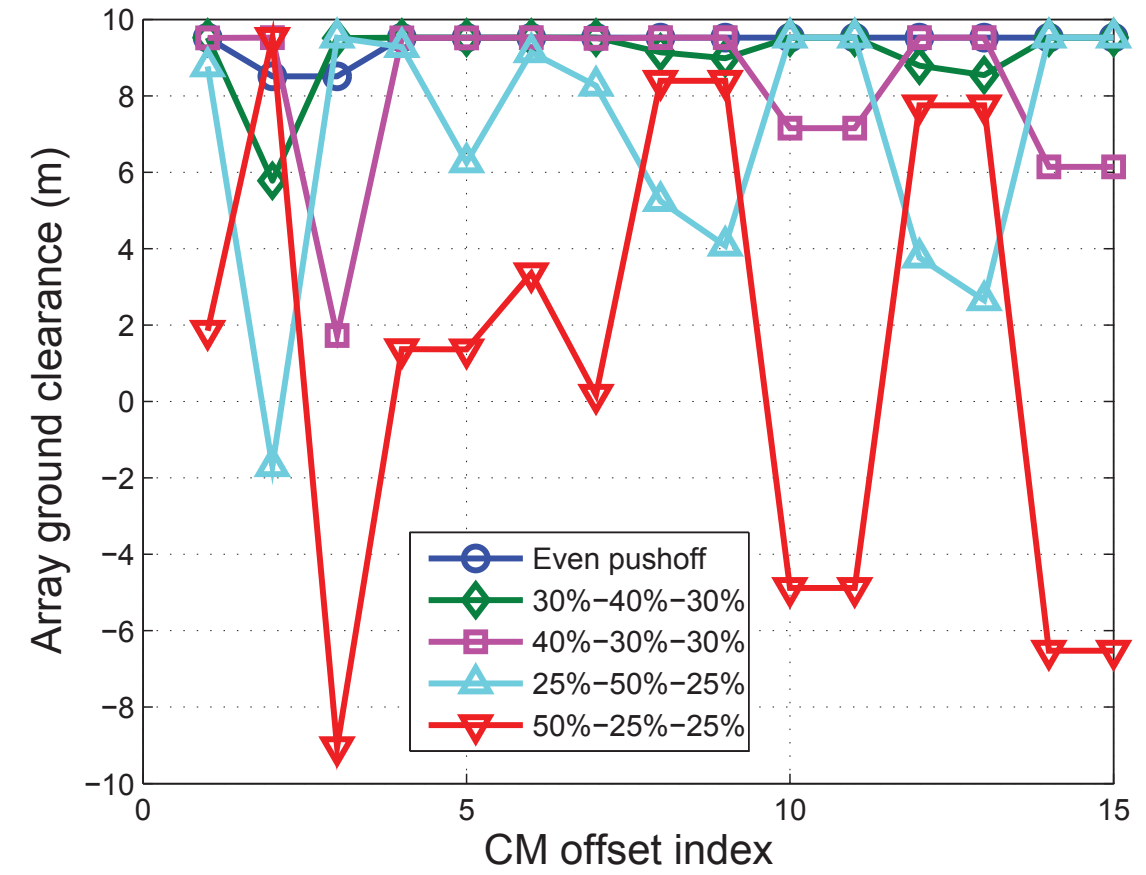

Figure 14: Worst case array ground clearance for combinations of CM offsets and push-off force distributions.

Fig. 15. It can be seen that the largest solar array tip acceleration is less than $0.007 \mathrm{~g}$, well within the 0.1-g threshold. It should be noted that this analysis assumes a rigid array structure, and thus, these accelerations are likely minimum values that will be experienced. The large flexible structure of the arrays will encounter some whipping effect that will increase the peak values.

\subsection{Thruster sizing}

Analysis is also performed investigating how the current RCS thrust level has to be scaled in order to achieve array ground clearance of $5 \mathrm{~m}$ for the entire trade space. The required scale factors for the five push-off force distributions are listed in Table 12. It can be seen that in the worst case when the push-off force distribution is 50\%-25\%-25\%, 4.1 times the current RCS thrust level is required to achieve a 5-m array ground clearance. If the push-off force distribution is $25 \%-50 \%$ - 
Table 11: Trade parameters in the worst case

\begin{tabular}{r|l}
\hline Parameter & Value \\
\hline \hline Boulder diameter & $4 \mathrm{~m}$ \\
Estimated density & $3 \mathrm{~g} / \mathrm{cc}$ \\
True density & $3.3 \mathrm{~g} / \mathrm{cc}$ \\
Boulder shape & 211 ellipsoid \\
Boulder orientation & Long axis perpendicular to array axis \\
CM Offset & $-0.5 \hat{\mathbf{b}}_{1}$ \\
Push-off force distribution & $50 \%-25 \%-25 \%$ \\
\hline
\end{tabular}

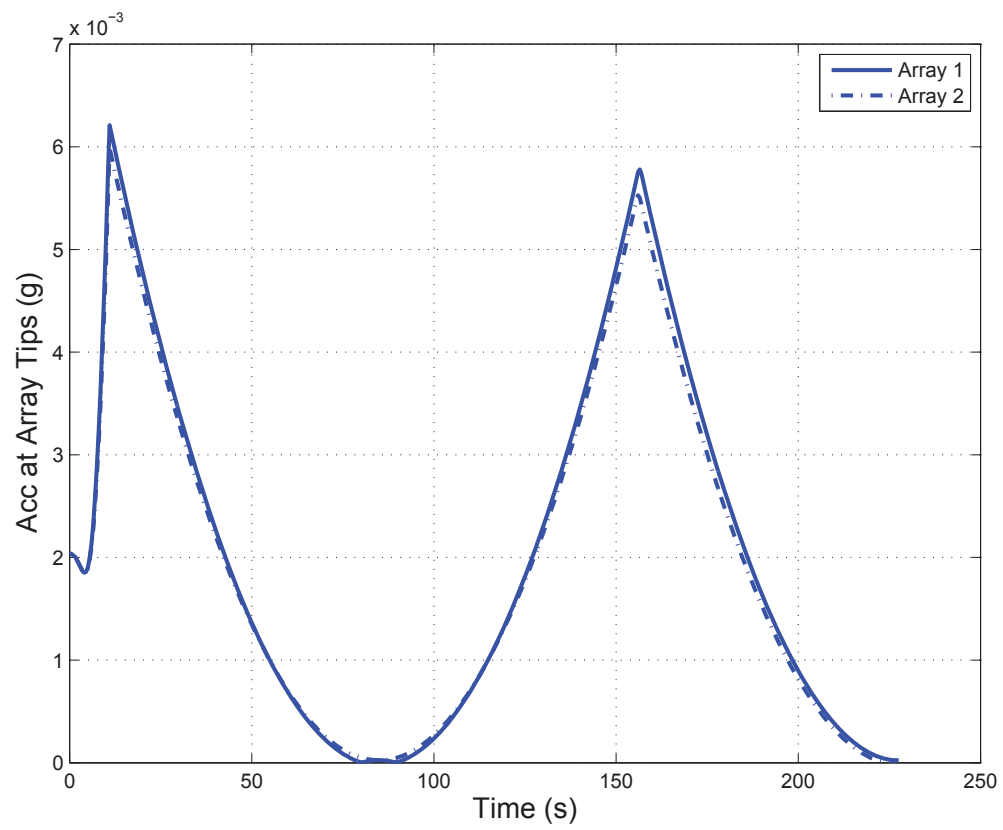

Figure 15: Worst case acceleration experienced by the tips of the solar arrays.

$25 \%$, a scale factor of 2.0 is required, and if the push-off force distribution is $40 \%-30 \%-30 \%$, a scale factor of 1.5 is required.

\section{Conclusions}

The ascent of a spacecraft retrieving a boulder up to $4 \mathrm{~m}$ in diameter from the surface of an asteroid is examined with regards to sensitivity of solar array ground clearance, attitude control authority, and accelerations at the array tips, to uncertainties in several parameters. Various boulder sizes, densities, shapes and orientations, CM offsets, and push-off force distributions are considered. It is shown through numerical simulation that with a $2-\mathrm{m}$ diameter boulder, the spacecraft attitude can be controlled such that the solar arrays have a ground clearance greater than $9.5 \mathrm{~m}$, with a 
Table 12: Thruster scaling to keep array ground clearance above $5 \mathrm{~m}$

\begin{tabular}{c|c|c|c|c|c}
\hline & \multicolumn{5}{|c}{ Push-off force distribution (\%) } \\
\cline { 2 - 6 } & even push-off & $30-40-30$ & $25-50-25$ & $50-25-25$ & $40-30-30$ \\
\hline \hline Scale factor & $1 \times$ & $1 \times$ & $2.0 \times$ & $4.1 \times$ & $1.5 \times$ \\
\hline
\end{tabular}

4.5-m margin over the 5-m safety requirement. For a 3-m diameter boulder, the solar array ground clearances are also above the 5-m requirement, but the margin is reduced to $0.13 \mathrm{~m}$. For a 4-m diameter boulder, there are cases in which the solar array ground clearances are less than $5 \mathrm{~m}$, and cases in which the arrays hit the ground. It is found that overestimating the density results in greater array ground clearance than underestimating the density. The cases involving a spherical boulder and a 221 ellipsoidal boulder have similar array ground clearances with differences less than $20 \mathrm{~mm}$. For a 211 ellipsoidal boulder, orienting the boulder's long axis parallel to the array axis results in a larger array ground clearance than a perpendicular orientation. In fact, the largest array ground clearance is obtained with a 211 ellipsoidal boulder in the parallel orientation. If the push-off force is distributed evenly or as 30\%-40\%-30\%, then all cases result in array ground clearances greater than $5 \mathrm{~m}$. It is found that the array tip accelerations are less than $0.007 \mathrm{~g}$, well within the $0.1-\mathrm{g}$ requirement. In order to keep the array ground clearance above $5 \mathrm{~m}$, the RCS thrust level needs to be scaled by $1.5,2.0$, and 4.1 times for push-off force distributions of $40 \%-30 \%-30 \%, 25 \%-50 \%-25 \%$, and $50 \%-25 \%-25 \%$, respectively.

\section{References}

[1] Mazanek, D. D., Merrill, R. G., Belbin, S. P., Reeves, D. M., Naasz, B. J., Abell, P. A., and Earle, K., "Asteroid Redirect Robotic Mission: Alternate Concept Overview," AIAA SPACE 2014 Conference and Exposition, Aug. 4-7, 2014, San Diego, CA.

[2] Roithmayr, C. M., Shen, H., Jesick, M., and Cornelius, D. M., "Catching a Rolling Stone: Dynamics and Control of a Spacecraft and an Asteroid," IAA-PDC13-04-27, 2013 Planetary Defense Conference, Flagstaff, AZ, April 15-19, 2013.

[3] Roithmayr, C. M., Shen, H., Jesick, M., and Cornelius, D. M., "Docking, Grappling, Capture, Control, and Alternative Approaches," Target NEO 2 Workshop, Washington, D.C., July 9, 2013.

[4] Belbin, S. P. and Merrill, R. G., "Boulder Capture System Design Options for the Asteroid Robotic Redirect Mission Alternate Concept Study," AIAA SPACE 2014 Conference and Exposition, Aug. 4-7, 2014, San Diego, CA.

[5] Yano, H., et al., "Touchdown of the Hayabusa Spacecraft at the Muses Sea on Itokawa," Science, Vol. 312, June 2006, pp. 1350-1353.

[6] Wie, B. and Barba, P. M., "Quaternion Feedback for Spacecraft Large Angle Maneuvers," Journal of Guidance, Control, and Dynamics, Vol. 8, No. 3, 1985, pp. 360-365. 
[7] Reeves, D. M., Naasz, B. J., Wright, C. A., and Pini, A. J., "Proximity Operations for the Asteroid Robotic Redirect Mission Alternate Concept," AIAA SPACE 2014 Conference and Exposition, Aug. 4-7, 2014, San Diego, CA.

[8] Fujiwara, A., et al., "The Rubble-Pile Asteroid Itokawa as Observed by Hayabusa," Science, Vol. 312, June 2006, pp. 1330-1334.

[9] Werner, R. A. and Scheeres, D. J., "Exterior Gravitation of a Polyhedron Derived and Compared with Harmonic and Mascon Gravitation Representations of Asteroid 4769 Castalia," Celestial Mechanics and Dynamical Astronomy, Vol. 65, No. 3, 1996/1997. 